\title{
Adenoviral Brachyury Vaccine ETBX-051
}

National Cancer Institute

\section{Source}

National Cancer Institute. Adenoviral Brachyury Vaccine ETBX-051. NCI Thesaurus. Code C143034.

A therapeutic cancer vaccine composed of a replication-defective, serotype 5 adenovirus (Ad5) with the viral genes early 1 (E1), early 2 b (E2b), and early 3 (E3) deleted, and the human transcription factor brachyury encoded, with potential immunostimulating and antineoplastic activities. Upon subcutaneous administration, the adenoviral brachyury vaccine ETBX-051 expresses the brachyury protein. The expressed brachyury may induce a cytotoxic T-lymphocyte (CTL)-mediated immune response ag ainst tumor cells expressing brachyury, thereby resulting in both immune-mediated inhibition of tumor cell proliferation and tumor cell death. Deletion of the E1, E2b and E3 genes from Ad5 prevents anti-adenovirus immune responses. Brachyury, a tumor-associated antigen (TAA) and member of the T-box family of transcription factors, is overexpressed in a variety of tumor types. It plays an important role in cancer progression and metastasis. 